\title{
Türk Atletlerde D Vitamini Reseptör Geni Fok1 (rs2228570) ve Bsm1 (rs1544410) Polimorfizmlerinin Analizi
}

\author{
Başak Funda EKEN ${ }^{*}$, Hazal GEZMİŞ ${ }^{* *}$, Canan SERCAN ${ }^{* * *}$, Sezgin KAPICI ${ }^{* * * *}$, \\ Özlem Moufti CHOUSEIN ${ }^{* * * * *}$, Deniz KIRAÇ ${ }^{* * * * * *}$, Serap AKYÜZ ${ }^{* * * * * * * *}$, \\ Korkut ULUCAN
}

\section{Öz}

Amaç: D vitamini kasların gelişmesinde, kasılmasında ve rejenerasyonunda görev alan önemli bir moleküldür. Çalışmamızda profesyonel Türk atletlerde D vitamin reseptör (VDR) Fok1 (rs 2228570) ve Bsmı (rs1544410) polimorfizmlerinin dağılımını araştırmayı amaçladık.

\footnotetext{
Özgün Araştırma Makalesi (Original Research Article)

Geliş / Received: 05.09.2018 \& Kabul / Accepted: 11.10.2018

* Doktora Öğrencisi, Marmara Üniversitesi, Diş Hekimliği Fakültesi, Tibbi Biyoloji ve Genetik Bölümü, İstanbul, Türkiye, E-posta: bfunda.eken@gmail.com, ORCID ID https://orcid.org/0000-0002-2690-8071

*** Doktora Öğrencisi, Yeditepe Üniversitesi, Tıp Fakültesi, Tıbbi Biyoloji Bölümü, İstanbul, Türkiye, E-posta: hazalgezmis@gmail.com, ORCID ID https://orcid.org/oooo-0003-3867-2155 *** Doktora Öğrencisi, Üsküdar Üniversitesi, Mühendislik ve Doğa Bilimleri Fakültesi, Moleküler Biyoloji ve Genetik Bölümü, İstanbul, Türkiye, E-posta: canan.sercan@uskudar.edu.tr ORCID ID https://orcid.org/0000-0002-2218-2234

***** Doktora Öğrencisi, Üsküdar Üniversitesi, Mühendislik ve Doğa Bilimleri Fakültesi, Moleküler Biyoloji ve Genetik Bölümü, İstanbul, Türkiye, E-posta: sezginkapici@gmail.com ORCID ID https://orcid.org/oooo-0002-3999-911X

****** Dr., Marmara Üniversitesi, Diş Hekimliği Fakültesi, Pedodonti Anabilim Dalı, İstanbul, Türkiye, E-posta: ozle-mc@hotmail.com, ORCID ID https://orcid.org/o00o-0002-3359-9350

****** Doç. Dr., Yeditepe Üniversitesi, Tıp Fakültesi, Tibbi Biyoloji Bölümü, İstanbul, Türkiye, E-posta: dyat@uskudar.edu.tr ORCID ID https://orcid.org/o000-0002-3599-7344 ******** Prof. Dr., Marmara Üniversitesi, Diş Hekimliği Fakültesi, Pedodonti Anabilim Dall, İstanbul, Türkiye, E-posta: sakyuz@marmara.edu.tr, ORCID ID https://orcid.org/o0oo-0002$1358-0150$

$\frac{13 * * * * * * * *}{*}$ Doç. Dr., Marmara Üniversitesi, Diş Hekimliği Fakültesi, Tıbbi Biyoloji ve Genetik Bölümü, İstanbul, Türkiye ; Üsküdar Üniversitesi, Mühendislik ve Doğa Bilimleri Fakültesi, Moleküler Biyoloji ve Genetik Bölümü, İstanbul, Türkiye, E-posta: korkutulucan@hotmail.com ORCID ID https://orcid.org/o0oo-0002-1304-9386
} 
Yöntem: Çalışmamıza 13 kadın ve 14 erkek atlet olmak üzere 27 sporcu katılmıştır. DNA izolasyonları sonrasında D vitamini reseptörü polimorfizmleri gerçek zamanlı PZR (RT-PCR) metodu ile saptanmıştır.

Bulgular: Fok1 polimorfizmi açısından atletlerin 12'si CC, 5’i CT ve 10'u ise TT genotipindedir. Kadın atletlerin 6'sı CC, 2'si CT ve 5'i ise TT genotipinde bulunmuştur. Erkek atletlerde 6 sporcu CC, 3 sporcu CT ve 5 sporcu ise TT genotipindedir. Bsm1 polimorfizmi için 9 atlet AA, 14'ü AG, 4'ü ise GG genotipindedir. Kadın atletlerin 3'ü AA, 8’i AG ve 2'si GG genotipindedir. Erkek atletlerin 6'sı AA, 6'sı AG ve 2'si GG genotipinde saptanmıştır.

Sonuç: Çalışma grubumuzda Fok1 polimorfizmi için CC genotipi ve C allelinin, Bsm1 içinde AG genotipinin ve A allelinin baskın olduğu gözlenmiştir. Bu çalışmanın $V D R$ geninin atletik performansa etkisinin araştırılması için yapılacak yeni çalışmalar için referans olacağını düşünmekteyiz.

Anahtar Sözcükler: D vitamini reseptörü, sporcular, spor genetiği, polimorfizm.

\title{
Analysis of Vitamin D Receptor Fok1 (rs2228570) and Bsm1 (rs1544410) Polymorphism in Turkish Athletes
}

\begin{abstract}
Aim: Vitamin D is an important molecule responsible for the development, contraction and regeneration of muscles. In this study, we aimed to research the distribution of vitamin $\mathrm{D}$ receptor (VDR) Fok1 (rs 2228570) and Bsm1 (rs1544410) polymorphisms in professional Turkish athletes.

Method: A total 27 athletes including 13 female and 14 male athletes participated in the study. Following DNA isolation, polymorphisms of VDR were determined by real-time PCR (RT-PCR).

Findings: 12 of the athletes have CC, 5 of them have CT and 10 of them have TT genotypes in terms of Fok1 polymorphism. 6 female athletes were determined as CC, 2 of them as CT and 5 of them as TT genotype. 6 male athletes were found as CC, 3 of them as CT and 5 of them as TT genotype. For Bsm1 polymorphism, 9 athletes have AA, 14 of athletes have AG and 4 of them have GG genotypes. 3 of the female athletes have AA, 8 of them have AG and 2 of them have GG genotypes. 6 of male athletes have AA, 6 of them have AG and 2 of them have GG genotypes.

Conclusion: In our study, it was observed that $\mathrm{CC}$ genotype and $\mathrm{C}$ allele for Fok1 polymorphism were dominant of AG genotype and A allele in Bsm 1. We believe that this study will be a reference for new studies to research the effect of VDR gene on athletic performance.
\end{abstract}

Keywords: Vitamin D receptor, athletes, sports genetic, polymorphism. 


\section{Giriş}

Atletik performans; sporcuların herhangi bir sportif faaliyeti sırasında gösterdikleri ve bu faaliyeti gerçekleştirebilmek için gerekli tüm mental ve fizyolojik performanslarının toplamı olarak kabul edilmektedir. Başarılı sporcuların beslenme, çalışma disiplini, motivasyonu ve istekleri gibi genetik yapı ile belirlenebilen özellikleri onların atletik performanslarının oluşması ve gelişmelerine etki eden faktörlerin başında gelmektedir ${ }^{1}$. Genetik bilgilerin daha iyi anlaşılması ve tanı teknolojilerinin gelişmesi ile atletik performansa etki eden ve etki etmeye aday olan genetik mekanizmaların analizi günümüzde spor genomiği çalışmalarının temelini oluşturmaktadır. Sadece fizyolojik özelliklerin değil, beslenme ve psikolojik faktörlerin de analizi artık büyük önem kazanmış, bireye özgü antrenman modelleri ve beslenme programları kişilerin genetik yapılarına uygun olarak hazırlanabilmektedir.

Sporcu metabolizmasında vitamin ve mineraller oldukça önemlidir. D vitamini, başlıca kemik ve kas gelişimini ve büyümesini düzenler, bu işlevlerinin yanında hücresel birçok metabolizmada önemli görevler üstlenen A, E, K vitaminleri gibi yağda çözünen sterol yapılı moleküller arasındadır. Aynı zamanda vücutta mineral dengesinin regülasyonunu böbrek ve bağırsakta kalsiyum ve fosforun emilimini sağlayarak gerçekleştirmektedir ${ }^{2}$. Bazı yazarlara göre ise D vitamini klasik vitamin tanımına uymadığından dolayı (klasik tanımda vitaminler eser miktarlarda bile metabolizmayı düzenleyen vücutta sentezi olmayan ve diyetle alınmadığı zamanlarda klinik sorunlara neden olan maddeler olarak tanımlanır.) vitaminden ziyade hormon özellikleri ile daha iyi örtüştüğü ve hormon olarak adlandırılmasının daha uygun olduğu bildirilmektedir3. Kas ve kemik gelişimindeki etkilerinden dolayı sporcuların atletik performanslarında ve sporcu sağlı̆̆ı açısından önemli etkileri bulunmaktadır.

D vitamini reseptörü (VDR) nükleer reseptör grubu üyesidir. İlk kez 1969 yılında tanımlanan nükleer hormon reseptör gen ailesinin bir üyesi olan VDR'yi kodlayan gen 12q13.11'de lokalizedir, $100 \mathrm{~kb}$ uzunluğunda olup üzerinde 100'den fazla polimorfizm tanımlanmıştır ${ }^{4,5}$. 11 ekzondan oluşan genin 2. ve 3. ekzonları DNA bağlanma bölgesini, 4. ve 9. ekzonları ise ligand bağlanma bölgesini kodlamaktadır. VDR'nin 2. ekzonunun 5' ucunda bulunan Fok1 polimorfizmi (rs2228570) başlangıç kodonuna denk gelmektedir. T>C baz değişikliği sonucunda ilk kodonda ATG-ACG dönüşümü olur ve 424 aminoasit uzunluğunda varyant polipeptit sentezlenir. Bu varyasyonun olmadığı 
durumda ise normal olarak kabul edilen 427 aminoasitlik polipeptit sentezlenir. Gen üzerinde bulunan diğer etkili bir polimorfizmi de Bsm1 polimorfizmidir. 8. intronda genin 3'-UTR bölgesine yakın bir lokasyonda yer almaktadır6. Bu bölge mRNA stabilitesine ve degrasyonunda rol oynadığı için gen ekspresyonu ile ilişkili olduğu tahmin edilmektedir. VDR Bsm1 (rs1544410) polimorfizminde A > G transisyonu sonucu meydana gelmektedir. VDR Bsmı polimorfizminde A allelinin mRNA'sının düşük

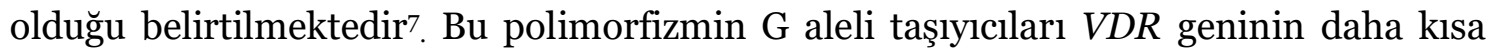
formunda olduğundan transkripsiyonel aktiviteyi de uyardığı düşünülmektedir. $V D R$ 'deki Bsml polimorfizminin ise kas kuvveti ile de ilişkisi bulunduğu belirtilmektedir8,9.

Atletik performansın oluşmasında ve gelişmesinde özellikle kas metabolizmasını optimal düzeyde olması beklenir. Egzersiz gibi aktivitelerin hücresel temellerinde genetik varyasyonların metabolizmaya etkisi oldukça önemlidir, bu yüzden genlerin en optimal formlarının sporcuların genotiplerinde yer alması beklenir. $\mathrm{Bu}$ çalışmanın amacı atletik performansın sağlanmasında ve sporcu sağlığı açısından önemli olan D vitamini metabolizmasina etki eden VDR Fok1 (rs2228570) ve Bsm1 (rs1544410) polimorfizmlerinin Türk atletlerdeki dağılımının incelenmesidir.

\section{Gereç ve Yöntem}

\section{Çalışma Grubu}

Çalışmamıza gönüllü olarak katılan, haftada en az 4 antrenman yapan, 18 yaş üstü, aralarında milli takım düzeyinde sporcu olan, 13’ü kadın 14’ü erkek olmak üzere toplam 27 profesyonel atlet katılmıştır. Çalışmamız ve çalışma protokolümüz, Helsinki Deklarasyonu-2 (2015) yönergelerine uygun olarak hazırlanmış ve Üsküdar Üniversitesi Girişimsel Olmayan Etik Kurulu tarafından onanmıştır. Çalışmaya gönüllü katılan sporculardan, çalışma öncesi yapılan analizler ve çıktıları hakkında detaylı bilgi verilmiş, kendilerinden imzalı bilgilendirme formları alınmıştır.

\section{DNA Genotiplemesi}

\section{DNA İzolasyonu}

Çalışmamıza katılan sporculardan alınan 1 cc periferik kan eldesi sonrasında lökosit DNA'ları ticari olarak satın alınan PureLink DNA izolasyon kitinin (Invitrogen, Van Allen Way Carlsbad, CA, USA) kullanıcı protokol aşamaları izlenerek tamamlanmıştır. 
$200 \mu \mathrm{L}$ periferik kan üzerine $20 \mu \mathrm{L}$ proteinaz $\mathrm{k}, 10 \mu \mathrm{L}$ RNAaz eklenerek vortekslendi ve 2 dk oda sicaklığında bekledikten sonra da homojen hale getirmek için $200 \mu \mathrm{L}$ bağlama tamponu eklendi ve karıştırıldı. $55^{\circ} \mathrm{C}$ su banyosunda $10 \mathrm{dk}$ inkübe edildikten sonra üzerine $200 \mu \mathrm{L}$ etanol eklenerek 5 sn vortekslendi ve filtreli tübe alındı. $10000 \mathrm{~g}$ 'de $1 \mathrm{dk}$ santrifüj edildikten sonra da süpernant kısmı atılarak kalan pellet kısmı üzerine $500 \mu \mathrm{L}$ yıkama tamponu eklenerek 1000og'de 1,15 sn santrifüj işlemi gerçekleştirildi. Yine süpernant kısmı alınarak üzerine yıkama tamponu 2 eklendi ve maksimum hızda $3 \mathrm{dk}$ santrifüj edildi. $80 \mu \mathrm{L}$ elüsyon tamponu eklenerek inkübe edildikten sonra maksimum hızda $1 \mathrm{dk}$ santrifüj edildi. Elde edilen DNA örnekleri, ilgili gen bölgelerinin genotipleme işlemlerinin tamamlanmasına kadar $-20^{\circ} \mathrm{C}$ de saklandı.

\section{VDR rs2228570 ve rs1544410 Genotiplerinin Belirlenmesi}

VDR Fok1 (rs2228570) ve Bsm1 (rs1544410) genotipleri, periferik kandan izole edilen DNA materyalinden 7500 Fast Real-Time PCR System (Applied Biosystems) cihazı ile Taqman Genotyping Assays (Applied Biosystems Foster City, CA, USA) genotipleme kitleri kullanılarak gerçekleştirilmiştir. Toplamda 10uL olacak şekilde $5 \mu \mathrm{L}$ master mix, $3,75 \mu \mathrm{L} \quad \mathrm{H}_{2} \mathrm{O}$, o, $25 \mu \mathrm{L}$ assay ve $1 \mu \mathrm{L}(10 \mathrm{ng})$ DNA kullanılarak ilgili bölgelerin genotipleme işlemleri tamamlanmıştır.

\section{Bulgular}

Çalışmamıza 14’ü (\%52) erkek, 13’ü (\% 48) kadın olmak üzere toplam 27 atlet katılmıştır. Tüm atletlerde VDR Fok1 (rs2228570) ve Bsm1 (rs1544410) polimorfizmlerin genotip ve allelik dağılımları sirasıyla Tablo 1 ve Tablo 2'de özetlenmiştir. Elde edilen sonuçlara göre çalışmaya katılan atletlerin toplamda 12'si CC, 5’i CT, 10’u ise TT genotipindedir. Fok1 polimorfizmi için elde edilen sonuçlara göre totalde kadın atletlerin 6 'sı CC, 2' si CT, 5 tanesi ise TT genotipindedir. Cinsiyete göre analiz edildiğinde ise 13 kadın sporcunun sprinter atletlerinin 4'ünde CC (\%15), 3'ünde TT (\%11) genotipi bulunurken, CT genotipine rastlanılmamıştır. Uzun mesafe koşucusu kadın atletlerin 2'sinde CC (\%7) ve 2'sinde CT (\%7) genotipi bulunurken, diğer 2 sporcuda ise (\%7) TT genotipi tespit edilmiştir. 14 erkek sporcunun sprinter atletlerin 3’ünde CC (\%11), 3’ünde CT (\%11), 4’ünde TT (\%15) genotipi bulunurken, uzun mesafe koşucusu sporcuların 3 'ünde CC (\%11), 1’inde ise TT genotipi tespit edilmiş olup, CT genotipine rastlanılmamıştır. Allelik dağılımlar incelendiğinde Fokı’in C alleli çalışma grubunda \%54 T alleli ise \%46 olarak bulunmuştur (Tablo 1). 
Tablo 1: Fok1 (rs2228570) polimorfizminin çalışma grubundaki dağılımı

\begin{tabular}{|l|l|l|l|l|l|l|}
\hline & Mesafe & CC & CT & TT & C & T \\
\hline $\begin{array}{l}\text { Kadın } \\
(\mathrm{n}=13)\end{array}$ & Sprinter & $4(\% 15)$ & - & $3(\% 11)$ & $8(\% 15)$ & $6(\% 11)$ \\
\cline { 2 - 7 } & Uzun mesafe & $2(\% 7)$ & $2(\% 7)$ & $2(\% 7)$ & $6(\% 11)$ & $6(\% 11)$ \\
\hline $\begin{array}{l}\text { Erkek } \\
(\mathrm{n}=14)\end{array}$ & Sprinter & $3(\% 11)$ & $3(\% 11)$ & $4(\% 15)$ & $9(\% 17)$ & $11(\% 20)$ \\
\cline { 2 - 7 } & Uzun mesafe & $3(\% 11)$ & - & $1(\% 4)$ & $6(\% 11)$ & $2(\% 4)$ \\
\hline Toplam & & $12(\% 44)$ & $5(\% 18)$ & $10(\% 37)$ & $29(\% 54)$ & $25(\% 46)$ \\
\hline
\end{tabular}

Bsm1 polimorfizmi için elde edilen bulgular incelendiğinde çalışmaya katılan atletlerin toplamda 9'unda (\%33) AA, 14'ünde (\%52) AG, 4’ünde (\%15) GG genotipi olduğu tespit edilmiştir. Cinsiyete göre ayrıldığında ise 13 kadın sporcunun sprinter sporcularının 3’ünde AA (\%11), 3’ünde AG, 1’inde (\%4) GG genotipi belirlenmiş olup; uzun mesafe koşucularında ise AA genotipine rastlanmazken, 5'inde AG (\%19), 1'inde GG genotipi \%4 oranında tespit edilmiştir. Erkeklerin ise sprinter sporcularının 2'sinde AA (\%7), 6'sinda AG (\%22), 2'sinde ise GG genotipi bulunurken, uzun mesafe atletlerde ise 4’ünde AA (\%15) genotipi bulunurken, AG ve GG genotipine rastlanılmamıştır. Allelik dağılımlar incelendiğinde Bsmı'in A alleli çalışma grubunda \%60, G alleli \%41 olarak bulunmuştur (Tablo 2).

Tablo 2: Bsm1 (rs1544410) polimorfizminin çalışma grubundaki dağılımı

\begin{tabular}{|l|l|l|l|l|l|l|}
\hline & Mesafe & \multicolumn{1}{|c|}{ AA } & AG & GG & A & G \\
\hline \multirow{2}{*}{ Kadın } & Sprinter & $3(\% 11)$ & $3(\% 11)$ & $1 \% 4)$ & $9(\% 17)$ & $5(\% 9)$ \\
\cline { 2 - 7 } & $\begin{array}{l}\text { Uzun } \\
\text { mesafe }\end{array}$ & - & $5(\% 19)$ & $1(\% 4)$ & $5(\% 9)$ & $7(\% 13)$ \\
\hline \multirow{2}{*}{ Erkek } & Sprinter & $2(\% 7)$ & $6(\% 22)$ & $2(\% 7)$ & $10(\% 19)$ & $10(\% 19)$ \\
\cline { 2 - 7 } & $\begin{array}{l}\text { Uzun } \\
\text { mesafe }\end{array}$ & $4(\% 15)$ & - & - & $8(\% 15)$ & - \\
\hline Toplam & & $9(\% 33)$ & $14(\% 52)$ & $4(\% 15)$ & $32(\% 60)$ & $22(\% 41)$ \\
\hline
\end{tabular}


Kombine genotip dağılımı ise Tablo 3’te özetlenmiştir. Fok1 ve Bsm1 polimorfizmlerinin kombine dağılımları değerlendirildiğinde en fazla genotip 7 bireyde $\mathrm{CC}+\mathrm{AA}$ ve $\mathrm{TT}+\mathrm{AG}$ genotipleri olarak bulunmuştur. $\mathrm{CT}+\mathrm{AA}$ genotiplerine ise hiçbir bireyde rastlanmamıştır

Tablo 3: Fok1 (rs2228570) ve Bsm1 (rs1544410) polimorfizmlerinin kombine dağılımı

\begin{tabular}{|l|l|l|l|}
\hline & \multicolumn{2}{|l|}{ Bsm1 (rs1544410) } & GG \\
\hline Fok1 (rs2228570) & AA & AG & 2 \\
\hline CC & 7 & 3 & 1 \\
\hline CT & - & 4 & 1 \\
\hline TT & 2 & 7 & \\
\hline
\end{tabular}

\section{Tartışma}

Kemik-mineral yoğunluğu ve sağlığı için gerekli olan biyoaktif moleküllerin en önemlisi olarak bilinen vitaminlerin başında D vitamini gelmektedir. Ayrıca sporcuların sadece kemik sağlı̆̆ının gelişmesi için değil sporcuların egzersiz sonrası oluşan enflamasyonu azaltmak bağışıklığını desteklemek gibi önemli görevlerinin olduğu da yapılan çalışmalarla belirtilmektedir ${ }^{10}$. Yapılan araştırmalar sonucunda normal şartlar altında D vitamini düzeyi için günlük $20 \mathrm{ng} / \mathrm{ml}$ kemik sağlı̆̆ 1 için yeterli olduğu bildirilmiş olsa da sporcuların bağışıklığını desteklemek ve egzersizle ilgili inflamasyonunu azaltmak için bu düzeyin $32-40 \mathrm{ng} / \mathrm{ml}$ gibi daha yüksek seviyelerde olması gerektiği belirtilmektedir. Ayrıca D vitamini eksikliği sonucu meydana gelen metabolizma problemleri düşünüldüğünde $\mathrm{D}$ vitaminin dokulara ulaşması ve reseptörüne bağlanmasının önemli bir yerinin olduğu belirtilmektedir. $\mathrm{Bu}$ nedenle $\mathrm{D}$ vitamini metabolizması için reseptörü üzerindeki fonksiyonel polimorfizmler oldukça önemli rol oynamaktadır ${ }^{11}$.

Çalışma grubumuzda Fok1 ve Bsm1 polimorfizmleri incelendiğinde Fok1 için CC genotipi ve C allelinin, Bsmı içinde AG genotipinin ve A allelinin baskın olduğu gözlenmiştir. $V D R$ atletik performans ilişkisinin belirlenmesinde çalışılan ilk polimorfizmlerinden biri Fokı'dir. Yapılan çalışmalarda Fok1 polimorfizminin CC homozigot genotipi bireylerde egzersiz ve beslenme ile birlikte kemik-mineral 
yoğunluğuna daha fazla oranda etki ettiği belirtilmektedir ${ }^{12}$. Ayrıca kronik obstrüktif akciğer hastalarında (KOAH) olduğu gibi sistemik hastalık gösteren bireylerde CC homozigotlarının, CT ve TT genotiplerine sahip olanlara göre daha zayıf kuadriseps kaslarına sahip olduğu belirtilmiştir ${ }^{13}$. Rabon-Stith ve ark. ${ }^{14}$ çalışmalarında sporcularda Fok1 polimorfizminin dayanıklılık antrenmanlarının kemik mineral yoğunluğuna daha fazla etki ettiğini ancak Fokı polimorfizminin ise aerobik antrenman ile ilişkisinin olmadı̆̆ını da belirtmiştir.

$V D R$ ile sistemik hastalıkların ilişkisi, yapılan birçok çalışma ile ortaya konmuştur. Bunların yanında atletik performans ile ilişkili $V D R$ çalışmaları da günümüze kadar farklı sportif branşlarda gerçekleştirilmiştir. Genç İtalyan erkek futbolcular üzerinde yapılan çalışmada ise araştırmacılar CC genotipini \%52, CT genotipini \%34 ve TT genotipini \%14 olarak bularak elde edilen genotip sonuçlarının futbola yatkınlıkta önemli bir belirteç olabileceğini belirtmişlerdir ${ }^{15}$. Benzer bir çalışmada Diogenes ve ark. ${ }^{16}$ tarafından 46 yetişkin Brezilyalı futbolcu üzerinde yapılmış, CC, CT ve TT genotip yüzdelerini sırasıyla \%41.3, \%47.8, \%10.9 olarak bulmuşlardır. CC genotiplerinin yüzdesel olarak yüksek olması bizim çalışmamız ile benzerlik göstermektedir. Massidda ve ark. ${ }^{17} 54$ İtalyan sporcu üzerinde yaptığı başka bir çalışmada ise CC genotipini \%46.3 olarak bularak CT (\%38.8) ve TT (\%14.8) genotiplerine kıyasla daha yüksek oranda bulmuşlardır. Bu sonuçlar Türk sporcular ile yaptığımız analiz çalışmaları ile benzerlik göstermekle birlikte genin yabanıl formu olan $\mathrm{T}$ allelinin yüzdesel anlamda düşük olmasının nedenlerini açıklamaktan uzaktır. Bu polimorfizmin hücresel etkilerine dair net sonuçların olmaması, C allelinin fiziksel aktiviteye yatkınlık sağladığı şeklinde yorumlamamıza neden olabilir, ancak $\mathrm{C}$ allelinin moleküler düzeyde etkisini net olarak bilinmemesi yorum atletik performansa etkisi bakımından yorum yapmamızı kisitlamaktadır.

Çalışma grubumuzda Bsmı genotipi incelendiğinde AG genotipinin daha baskın olduğu görülmektedir. Cinsiyet ve koşu mesafelerine göre incelendiğinde kadın uzun mesafe ve erkek sprinterlerde AG genotipinin en yüksek oranda olduğu belirlenmiştir. Allelik formlara bakıldığında ise AA allelinin toplamda \%6o'lık orana sahip olduğu tespit edilmiştir. İlginç olarak uzun mesafe erkek sporcularda GG alleli hiç görülmemiştir (Tablo 2). A allelinin transkripsiyon oranının $\mathrm{G}$ alleline kıyasla daha düşük olmasının 
bu allelin özellikle uzun mesafe koşucuları için bir dezavantaj olduğunu düşündürmüştür.

70 yaş üzeri 501 sağlıklı kadın üzerinde yapılan çalışmada $B s m 1$ polimorfizminde G alleli bulunduranların bulundurmayanlara göre daha kuvvetli kas yapısına sahip olduğu belirlenmiştir ${ }^{18}$. Benzer sonuçlar, Hopkinson ve ark.13 tarafından da bulunmuştur. Yaşlı erkeklerde yapılan çalışmada ise izometrik kas kuvveti ve VDR genotipi arasında korelasyon kurulamamıştır ${ }^{19}$. Yapılan diğer bir öncü çalışmada ise menopoz öncesi 170 İsveçli kadında Bsmı polimorfizmi ve kas gücü arasındaki ilişkiyi değerlendirilmiş, AA genotipli kadınların diğer genotiplere sahip bireylere göre hamstring kas kuvveti bakımından daha kuvvetli olduğu belirtilirken, genotipleri ile kuadriseps kas kuvvetleri arasında herhangi bir bağlantı bulunmadığını bildirmişlerdir²o. Bizim kohortumuzda A alleli yüzdesel olarak $\mathrm{G}$ alleline, AG genotipi ise diğer genotiplere göre daha yüksek çıkmıştır. $G$ allelinin ekspresyon düzeyinin yüksek olması açısından sonuçlarımız atletik performans Bsmı polimorfizm ilişkisini desteklemekle beraber A allel sıklığını yüksek olması ise desteklememektedir.

Bsm1 ve Fok1 polimorfizmlerinin özellikle ağır egzersiz yapan sporcularda stres kırık riskini artırabileceği ve sağlıklı antrenman programlarının oluşturması için de bu genetik varyasyonların analiz edilmesi gerektiği bildirilmektedir ${ }^{21}$. 385 İsrail askerler üzerinde yapılan çalışmada içlerinde $V D R$ geninin de bulunduğu 17 gen analiz edilmiş, $V D R$ 'nin stres kırık riskini oluşturabileceği bu çalışma kohortunda belirlenmiştir ${ }^{22}$. $V D R$ polimorfizmlerinin (Bsm1, Fok1 ve Apal) etkisi jimnastikçiler üzerinde analiz edilmiş, ancak VDR genotipleri ile atletik performans arasında genotip açıdan korelasyon bulunamamıştır ${ }^{23}$.

Çalışma kohortumuzda Fok1 ve Bsmı polimorfizmlerini kombine dağılıma göre değerlendirildiğinde en fazla genotip 7 bireyde $\mathrm{CC}+\mathrm{AA}$ ve $\mathrm{TT}+\mathrm{AG}$ olarak tespit edilmiştir. $\mathrm{CT}+\mathrm{GG}$ ve $\mathrm{TT}+\mathrm{GG}$ genotipleri ise 1 sporcuda bulunmuştur. $\mathrm{CT}+\mathrm{AA}$ genotipleri ise hiçbir bireyde gözlenmemiştir. Elde edilen veriler sonucunda $\mathrm{CC}+\mathrm{AA}$ ve TT+AG gen kombinasyonları atletik performansa VDR metabolizması yönünden yatkınlık sağladığını düşünmekteyiz. Ancak Bsmı ve Fok1 haplotiplerini içeren genotipik ve fenotipik çalışmaların literatürde bulunmaması kombine gen etkilerinin tarafımızca yorumlanmasını zorlaştırmaktadır. 


\section{Sonuç}

Atletik performansın belirlenmesinde genetik faktörler giderek önem kazanmaktadır. Atletik performans multifaktöriyel özellik göstermektedir. $\mathrm{Bu}$ yüzden tek gen analizlerinden ziyade gen gruplarının analiz edilmesinin daha gerçekçi sonuçlar vereceği tahmin edilmektedir. $\mathrm{Bu}$ çalışmaların gerçekleştirilmesi için Türk sporculardaki gen kombinasyonlarının belirlenmesi büyük önem taşımaktadır. $\mathrm{Bu}$ yüzden biz bu çalışmamızda analiz edilen parametreleri sedanter bireyler ile karşılaştırmak yerine sadece dallarında başarılı sporcular üzerindeki dağılımlarını belirlemeyi hedefledik. Sonuçlarımız, gerek Fok1 gerekse Bsm1 polimorfizmleri açısından ekspresyon düzeyi yüksek allellerin saptanması hipotezini desteklememiştir, ancak ilgili genetik polimorfizmlerin etkilerinin moleküler düzeyde net olmaması ve kohortumuzun az sayıda ki sporcudan oluşması sonuçlarımızın etkilerini anlamlandırmamızda kısıtlayıcı bir engel olarak görülmektedir. Bu çalışmanın daha yüksek denek içeren benzer çalışmalara örnek olması, farklı spor dalları ile uğraşan sporcular üzerinde tekrarlanması ve yapılacak ek çalışmalar ile $V D R$ geninin atletik performansa etkisinin daha net belirlenmesini ümit etmekteyiz.

\section{KAYNAKLAR}

1. Ulucan K, Yalcin S, Akbas B, Konuk M. Analysis of solute carrier family 6 member 4 gene promoter polymorphism in young turkish basketball players. The Journal of Neurobehavioral Sciences. 2014;1(1):37-40. doi: 10.5455/JNBS.1403730925.

2. Holick MF. Vitamin D deficiency. N Engl J Med. 2007;357:266-281. doi: 10.1056/NEJMrao70553.

3. Sözen T. D hormonu: Güncel gelişmeler. Hacettepe Medical J. 2011;42:14-27.

4. Norman AW. Vitamin D receptor: new assignments for an already busy receptor. Endocrinology. 2006;147:5542-5548. doi: 10.1210/en.2006-0946.

5. Eken BF, Sercan C, Gezmiş H, et al. D Vitamini Reseptörü rs1544410 polimorfizminin diş çürüğü oluşumuna etkisi. European Journal of Research in Dentistry. 2018;2(1):1-5. doi: 10.12990/MDJ.2018.13. 
6. Ulucan K, Akyüz S, Özbay G, Pekiner FN, Güney AI. Evaluation of Vitamin D Receptor (VDR) gene polymorphisms (FokI, TaqI and ApaI) in a family with dentinogenesis imperfecta. Cytology and Genetics. 2013;47(5):282-286. doi: 10.3103/Soo95452713050101.

7. Qin X, Lu Y, Qin A, et al. Vitamin D receptor BsmI polymorphism and ovarian cancer risk: a meta-analysis. International Journal of Gynecological Cancer. 2013;23(7):1178-1183. doi: 10.1097/IGC.obo13e31829db839.

8. Uitterlinden AG, Fang Y, Bergink AP, van Meurs J, Leeuwen H, Pols H. The role vitamin D receptor gene polymorphism in bone biyology. Molecular and Cellular Endocrinology. 2002;197(1-2):15-21. doi: 10.1016/So3037207(02)00274-5.

9. Valdivielso JM, Fernandez E. Vitamin D receptor polymorphisms and diseases. Clinica Chimica Acta. 2006;371(1-2):1-12. doi: 10.1016/j.cca.2006.02.016.

10. Larson-Meyer DE, Willis KS. Vitamin D and athletes. Current Sports Medicine Reports. 2010;9(4):220-226. doi: 10.1249/JSR.obo13e3181e7dd45.

11. Sercan C, Yavuzsoy E, Yüksel İ, et al. Sporcu sağlığı ve atletik performansta D vitamini ve reseptörünün önemi. Clinical Experimental Health Sciences. 2015;5(4):259-264. doi: 10.5455/musbed.20150831013319.

12. Takamura $\mathrm{O}$, Ishii $\mathrm{T}$, Ando $\mathrm{Y}$, et al. Potential role of vitamin $\mathrm{D}$ receptor gene polymorphism in determining bone phenotype in young male athletes. $J$ Appl Physiol. 2002;93(6):1973-1979. doi: 10.1152/japplphysiol.oo663.2002.

13. Hopkinson N, Li K, Kehoe A, et al. Vitamin D receptor genotypes influence quadriceps strength in obstructive pulmonary disease. Am J Clin Nutr. 2008;87:385-390. doi: 10.1093/ajen/87.2.385.

14. Rabon-Stith KM, Hagberg JM, Phares DA, et al. Vitamin D receptor FokI genotype influences bone mineral density response to strength training, but not aerobic training. Exp Physiol. 2005;90(4):653-661. doi: 10.1113/expphysiol.2005.030197.

15. Micheli ML, Gulisano M, Morucci G, et al. Angiotensin-converting enzyme vitamin D receptor gene polymorphisms and bioelectrical impedance analysis in 
predicting athletic performances of Italian young soccer players. $J$ Strength Cond Res. 2011;25(8):2084-2091. doi: 10.1519/JSC.obo13e31820238aa.

16. Diogenes ME, Bezerra FF, Cabello PH, et al. Vitamin D receptor gene FokI polymorphisms influence bone mass in adolescent football (soccer) players. Eur J Appl Physiol. 2010;108(1):31-38. doi: 10.1007/s00421-009-1191-6.

17. Massidda M, Scorcu M, Calò CM. New genetic model for predicting phenotype traits in sports. Int J Sports Physiol Perform. 2014;9(3):554-560. doi: 10.1123/ijspp.2012-0339.

18. Geusens P, Vandevyver C, Vanhoof J, Cassiman JJ, Boonen S, Raus J. Quadriceps and grip strength are related to vitamin D receptor genotype in elderly nonobese women. J Bone Miner Res. 1997;12(12):2082-2088. doi: 10.1359/jbmr.1997.12.12.2082.

19. Roth SM, Zmuda JM, Cauley JA, Shea PR, Ferrell RE. Vitamin D receptor genotype is associated with fat-free mass and sarcopenia in elderly men. Journal of Gerontology . 2004;59(1):10-15. doi: 10.1093/gerona/59.1.B10.

20. Grundberg E, Brandstrom H, Ribom EL, Ljunggren Ö, Mallmin H, Kindmark A. Genetic variation in the human vitamin D receptor is associated with muscle strength, fat mass and body weight in Swedish women. European Journal of Endocrinology. 2004;150(3):323-328.

21. McClung JP, Karl JP. Vitamin D and stress fracture: the contribution of vitamin D receptor gene polymorphism. Nutrition Reviews. 2010;68(6):365-369. doi: 10.1111/j.1753-4887.2010.00295.x.

22. Yanovich R, Friedman E, Milgrom R, Oberman B, Freedman L, Moran DS. Candidate gene analysis in Israeli soldiers with stress fractures. Journal of Sports Science and Medience. 2012;11:147-155.

23. Morucci G, Punzi T, Innocenti G, Gulisano M, Ceroti M, Pacini S. New frontiers in sport training: genetics and artistic gymnastics. The Journal of Strength and Conditioning Research. 2014;28(2):459-466. doi: 10.1519/JSC.obo13e31829aad65. 